\title{
Citogenética de Quirópteros: Métodos e Aplicações.
}

\author{
Marileila Varella-Garcia ${ }^{1}$ \\ Valdir Antonio Taddei ${ }^{2}$
}

\begin{abstract}
Information about standard karyotypes, G-band, C-band and Ag-NOR staining patterns and other chromosomal data are reviewed for species of the New World bats. Techniques for collecting and processing the specimens, for the preparation of $G$-and $C$-band chromosomes and for staining of nucleolus organizer regions are described. Systematic implication are also discussed.
\end{abstract}

\section{INTRODUÇÃO}

Os quirópteros são mamifferos com características morfológicas e fisiológicas peculiares, que os capacitam ao verdadeiro vôo. A maioria das espécies tem o poder de ecolocalização, o que lhes permite ocupar abrigos menos expostos à predação e à competição, bem como explorar de modo mais eficiente os recursos oferecidos pelo meio, devido a diversificação de seus hábitos alimentares. Consequentemente, os quirópteros constituem um grupo bem sucedido, representado nas regiões temperadas e tropicais de todos os continentes e, em muitas áreas, são os mamiferos mais freqüentes e com maior diversidade de espécies.

$\mathrm{Na} 10^{\mathrm{a}}$. edição do Systema Naturae de Lineu, publicada em 1758, já haviam sido classificadas sete espécies de morcegos, de acordo com o sistema binominal de nomenclatura zoológica atualmente utilizado (cf. KOOPMAN e JONES JR., 1970). Recentemente tem sido considerado que a ordem Chiroptera, subdividida nas subordens Megachiroptera e Microchiroptera, engloba aproximadamente 900 espécies, distribuĭdas em 175 gêneros de 17 familias (KOOPMAN, 1984).

A subordem Megachiroptera é constituĩda apenas pela familia Pteropodidae, que reune 42 gêneros e cerca de 160 espécies. Sua distribuição restringe-se às regiões tropicais e subtropicais da África, Sudeste da Ásia, Austrália, Samoa e Ilhas Carolinas (KOOPMAN, 1970) e alguns de seus membros são de grande porte, podendo alcançar até $170 \mathrm{~cm}$ de envergadura. A maioria dos Pteropodidae tem hábito alimentar frugivoro, mas as espécies de Macroglossinae alimentam-se basicamente de pólen e néctar (WALKER, 1975).

${ }^{1}$ Departamento de Biologia, Instituto de Biociências, Letras e Ciências Exatas - UNESP, 15055 São José do Rio Preto - SP.

${ }^{2}$ Departamento de Zoologia, Instituto de Biociências, Letras e Ciências Exatas - UNESP, 15055 São José do Rio Preto-SP. 
A subordem Microchiroptera inclui 16 familias, das quais 9 ocorrem nas Américas e todas têm representantes no Brasil (Tabela I). A maioria dos morcegos alimenta-se de insetos e, nessa categoria, merecem destaque as familias Vespertilionidae e Molossidae, cujas espécies podem constituir colônias numerosas, às vezes com cetenas e até milhões de indivĭduos. Na familia Phyllostomidae, por outro lado, há grande diversificação de hábitos alimentares e são encontrados nectarívoros, polinívoros, frugivoros, insetivoros, carnivoros, onivoros e hematófagos. As duas espécies de Noctilionidae consomem insetos, mas Noctilio leporinus inclui também peixes em sua dieta (TADDEI, 1983, para referências).

Em decorrência de seus hábitos alimentares, os morcegos desempenham um importante papel no controle de insetos e na polinização e dispersão de sementes de numerosas espécies vegetais. No entanto, podem ser reservatórios naturais de agentes infecciosos, como o virus da raiva paralitica e o Trypanosoma cruzi e, às vezes, seus abrigos naturais propiciam condições favoráveis à proliferação de fungos patogênicos, como o Histoplasma capsulatum, causador da histoplasmose (CONSTANTINE, 1970). Além disso, fezes de morcegos acumuladas nos telhados das residências foram identificadas como potentes alérgenos, induzindo asma e rinite (EL-ANSARY et al. 1987).

A importância desses animais, dos pontos de vista ecológico, econômico e médico-sanitário, aliada ao conjunto de características peculiares que apresentam, tornaram-nos intensamente investigados sob os enfoques morfológico, fisiológico, ecológico e sistemático (SMITH, 1972, TADDEI, 1973, 1976; HANDLEY JR., 1976; SAZIMA, 1978; FREEMAN, 1981; WILLIG, 1983; TADDEI et al., 1986; WILLIAMS, 1986, entre outros). No entanto, ainda há problemas taxonômicos não resolvidos e as relações filogenéticas propostas para as espécies, os gêneros, as familias e as subordens incluem hipóteses não confirmadas.

A descrição das espécies da ordem Chiroptera tem sido feita quase que exclusivamente com base em características morfológicas e métricas, avaliadas principalmente no crânio. Todavia, como esses animais estão entre os grupos de mamiferos mais antigos e mais divergentes, há dificuldade na identificação das relações filogenéticas com apoio apenas em detalhes intensamente envolvidos no processo adaptativo. Por isso, é importante a análise de outros aspectos, entre os quais destaca-se a identificação dos cariótipos, que permite avaliar a intensidade e os padrões da evolução cromossômica na ordem.

Os mais antigos estudos citológicos com morcegos, realizados de 1910 a 1950 , relatavam os números cromossômicos encontrados em material testícular de espécies européias e africanas (WAINBERG, 1966, para referências). Três espécies da Argentina, Dasypterus ega (= Lasiurus ega), Lasiurus borealis e Promops nasutus, foram os primeiros representantes sul-americanos analisados cromossomicamente, ainda em preparações muito precárias de testículos (WAINBERG, 1966).

A partir do final da década de 60 surgiram publicações descrevendo o cariótipo de dezenas de espécies americanos das familias Vespertilionidae (BAKER \& PATTON, 1967), Phyllostomidae (BAKER, 1967, 1970; HSU et al., 1968; FORMAN et al., 1968; BAKER \& HSU,1970) e outras (BAKER, 1970; BAKER \& HSU, 1970) e também de espécimes europeus (cf. CAPANNA e CIVI- 
TELLI, 1970). Esses resultados já foram obtidos em preparação de medula óssea ou de culturas de células pulmonares, que forneciam informações sobre o número e o tamanho dos cromossomos e permitiam uma melhor visualização da sua morfologia.

Nessa mesma época foram publicados os primeiros resultados de estudos com morcegos brasileiros, por YONENAGA (1968), YONENAGA et al. (1969) e BEÇAK et al. $(1968,1969)$. YONENAGA et al. descreveram os cariótipos de sete espécies de Phyllostomidae e uma de Noctilionidae, das quais quatro (Anoura caudifer, Phyllostomus hastatus, Chrotopterus auritus e Noctilio leporinus) até então não conhecidos. BEÇAK et al. discutiram o mecanismo de determinação do sexo em Artibeus lituratus e mostraram o pareamento do trivalente XY $\mathrm{XY}_{1} \mathrm{Y}_{2}$ na meiose dos machos.

Pouco mais tarde, TOLEDO (1973) apresentou o estudo citogenético de 21 espécies de morcegos brasileiros, das quais cinco inéditas (Histiotus velatus, Molossus ater, Micronycteris minuta, Eumops auripendulus e Vampyrops lineatus), analisando cromossomos mitóticos e meióticos em fragmentos de baço, fĭgado e testículo esmagados.

Esses primeiros etudos cromossômicos, apesar das limitações técnicas a que estavam sujeitos, já apresentavam interessantes resultados, tanto em relação à taxonomia e filogenia de grupos, como aos aspéctos citogenéticos. Assim, os achados cariotípicos reforçaram as propostas da inclusão da familia Desmodontidae como uma subfamilia de Phyllostomidae (FORMAN et al., 1968) e da sub-familia Sturnirinae na Stenodermatinae (BAKER,1967), e da sinonimia entre os gêneros Dasypterus e Lasiurus (TOLEDO, 1973). A similaridade na morfologia cromossômica embasou discussões sobre as relações filogenéticas entre os Molossidae (WAINBERG et al., 1974), entre os Vespertilionidae (ANDO et al., 1977), entre os Rhinolophidae (ANDO et al., 1980b, HARADA et al., 1985), e entre os Phyllostomidae, estes principalmente nas subfamilias Carolliinae (BAKER \& BLEIER, 1971), Stenodermatinae (BAKER, 1973) e Desmondontinae (CADENA \& BAKER, 1976).

Os aspectos citogenéticos mais destacados consistiram na identificação de polimorfismos cromossômicos por rearranjos robertsonianos (fusões e fissões cêntricas) e inversões pericêntricas em várias espécies, como Macrotus waterhousii (BAKER, 1967), Rhogeessa tumida (BAKER, 1970), Ectophylla macconnelli (BAKER \& HSU, 1970), Uroderma magnirostrum (BAKER \& LOPES, 1970a). Mimon crenulatum (BAKER et al., 1972) e Rhinophylla pumilio (TOLEDO, 1973).

Além disso, muitas observações foram feitas sobre o mecanismo de determinação sexual, devido a ocorrência de translocações entre o cromossomo X e autossomos em várias espécies, como as do gênero Artibeus (BEÇAK et al., 1968, 1969) e Carollia (PATTON \& GARDNER, 1971).

No entanto, certas conclusões foram dificultadas e mesmo impossibilitadas pelas deficiências metodológicas, até o desenvolvimento de técnicas que permitiam a marcação diferencial de regiões cromossômicas. Entre essas, incluem-se as que promovem a diferenciação longitudinal dos cromossomos 
(bandamentos $\mathrm{G}, \mathrm{R}$ e Q) e a marcação das regiões de heterocromatina constitutiva (bandamento $\mathrm{C}$ ) e organizadoras do nucléolo (bandamento Ag-NOR). As primeiras informações citogenéticas em morcegos, obtidas pelas técnicas de bandamento G e C, foram divulgadas por PATHAK et al., (1973). STOCK (1975), OBARA (1976) e BICKHAM \& BAKER (1977). GOODPASTURE \& BLOOM (1975) e SITES JR. et al. (1981) apresentaram os primeiros dados obtidos pela técnica Ag-NOR, e KASAHARA \& DUTRILLAUX (1983), VOLLETH (1985) e TUCKER (1986) publicaram informações sobre padrões de bandamento $\mathrm{R}$ e $\mathrm{Q}$.

\section{Metodologia para o Estudo Citogenético em Quirópteros}

\subsection{Coleta}

Os espécimes são coletados preferencialmente com o uso de redes de neblina ("mist nets"), dispostas nas áreas próximas às fontes de alimentos, às aberturas de abrigos diurnos e em possiveis rotas de vôo. Nas coletas realizadas diretamente nos refúgios diurnos, pode-se utilizar as redes de neblina e puçás, sendo conveniente o uso de respiradores para evitar riscos de contaminação com esporos do fungo Histoplasma capsulatum. A vacinação preventiva contra o vĭrus da raiva é, muitas vezes, indispensável.

Os animais são retirados da rede, tendo o coletor as mãos protegidas por luvas de raspa de couro, e transportados ao laboratório em pequenas gaiolas, recebendo alimentação adequada até o seu sacrifício.

\subsection{Processamento}

Geralmente no dia subsequente à coleta, injeta-se subcutaneamente, na região dorsal do animal, $0,2 \mathrm{ml}$ de solução de fermento glicosado ( $3 \mathrm{~g}$ fermento: $2 \mathrm{~g}$ dextrose: $12 \mathrm{ml} \mathrm{H}_{2} \mathrm{O}$ ) para cada $25 \mathrm{~g}$ de peso corporal (LEE \& ELDER, 1980). No dia seguinte de manhã, após 12 a 24 horas da injeção do indutor mitótico, injeta-se intraperitonialmente $0,2 \mathrm{ml}$ de solução de colquicina a $0,5 \%$, para cada $25 \mathrm{~g}$ peso corporal, a fim de inibir o processo de divisão celular por interferência na formação do fuso mitótico.

Os animais são sacrificados após 40 a 50 minutos da aplicação de colquicina e remove-se o úmero esquerdo, deixando a porção direita integra para permitir as medidas comuns nos estudos taxonômicos. Expõe-se a medula óssea, liberando os feixos musculares e tendões e uma lasca das epifises, e aspira-se com seringa, depositando-a em 3 a $4 \mathrm{ml}$ de solução de Hanks. Ressuspende-se até obter uma suspensão celular homogênea.

\subsection{Preparações cromossômicas}

Após centrifugações a cerca de $1000 \mathrm{rpm}$ por 5 minutos e retirada do sobrenadante, introduz-se em cada tubo cerca de $4 \mathrm{ml}$ de solução hipotônica $(\mathrm{KCL}$ a $0,075 \mathrm{M})$, ressuspende-se e incuba-se o material a $37^{\circ} \mathrm{C}$, por cerca de 20 minutos. Esse tempo pode variar em função da espécie e da qualidade 
de células do sedimento e, quando há grande quantidade de células, convém manter o tratamento hipotônico por até 30 minutos.

A fixação é feita com metanol acético 3:1 recém-preparado, para evitar hidratação, usando-se $6 \mathrm{ml}$ para cada tubo e realizando-se três ou quatro trocas de fixador, sempre ressuspendendo delicadamente a suspensão celular para evitar a ruptura das células em divisão. Finalmente adiciona-se cerca de $0,5 \mathrm{ml}$ de fixador por tubo e goteja-se 3 a 4 gotas da suspensã̉o em lâmina úmida e gelada, de uma altura aproximadamente de $20 \mathrm{~cm}$. As lâminas são secas na vertical, à temperatura ambiente.

O material para ser analisado em coloração usual é previamente hidrolizado em $\mathrm{HCl} 1 \mathrm{~N}$, a $60^{\circ} \mathrm{C}$, por 7 minutos e lavado em $\mathrm{H}_{2} \mathrm{O}$ gelada. A coloração é feita com solução de Giemsa tamponada $(\mathrm{pH} 6,8)$ a $2 \%$, por cerca de 7 minutos.

\subsection{Bandamento cromossômico}

Entre as técnicas utilizadas rotineiramente destacam-se o bandamento G, para identificação de todos os cromossomos, e os bandamentos $\mathrm{C}$ e Ag-NOR, que marcam regiões especifficas.

Para obtenção de bandas G segue-se a técnica de DeGROUCHY \& TURLEAU (1977), com modificações. O material é hidratado em banhos rápidos de álcool 50\% e água destilada, e mergulhado em tampão Sorensen $(\mathrm{pH} 6,8)$ por no mínimo 30 minutos. A seguir, é introduzido em solução de tripsina a $0,2 \%$, por tempo variável de acordo com o periodo decorrido de fixação, a espécie e as condições ambientais. Geralmente, à temperatura de $24^{\circ} \mathrm{C}$ e com lâminas de 10 dias, obtém-se bons resultados com cerca de 10 segundos de tratamento com a tripsina. A ação da tripsina é interrompida com banho em solução salina (PBS), por 2 minutos. A seguir, processa-se a coloração com solução de Giemsa a $2 \%$, por 8 minutos. A solução de Giemsa deve ser preparada imediatamente antes de ser utilizada.

O bandamento $\mathrm{C}$ é obtido por modificações na técnica de SUMNER (1972). Hidroliza-se previamente o material em $\mathrm{HCl}$ a $0,2 \mathrm{~N}$ por 15 minutos, à temperatura ambiente. Lava-se em água desionizada e pinga-se várias gotas de solução de $\mathrm{Ba}(\mathrm{OH})_{2}$ a $5 \%$, formando um filme bem espesso, que é coberto com uma ou duas lamínulas. $\mathrm{O}$ tempo de exposição ao $\mathrm{Ba}(\mathrm{OH})_{2}$ vai depender do perioodo decorrido da fixação do material, obtendo-se bons resultados com cerca de 10 minutos de tratamento em lâminas de 11 a 12 dias, mantidas à temperatura ambiente, e tempos maiores, em lâminas mais velhas. Para retirar a solução de $\mathrm{Ba}(\mathrm{OH})_{2}$ introduz-se a lâmina, na posição horizontal, sob um fio de água, de forma a retirar a laminnula sem deixar que o bário fique aderido sobre o material, o que impede a análise. Após lavagem em $\mathrm{H}_{2} \mathrm{O}$ destilada e $\mathrm{H}_{2} \mathrm{O}$ desionizada gelada, incuba-se em $2 \times \mathrm{SSC}$ por 10 minutos, à temperatura ambiente, e por 60 minutos, a $60^{\circ} \mathrm{C}$. A seguir desidrata-se o material em alcóois $70 \%$ e $95 \%$ e cora-se em solução de Giemsa tamponada a $2 \%$, por 15 minutos.

A marcação das regiões organizadoras do nucléolo (RONs) segue basicamente a técnica proposta por HOWELL \& BLACK (1980). Hidroliza-se o material em $\mathrm{HCl}$ a $1 \mathrm{~N}$, a $60^{\circ} \mathrm{C}$, por 10 minutos, interrompendo-se a hidrólise com banho em água desionizada gelada. Pinga-se uma gota de gelatina formalizada a 
$1 \%$ e uma gota de solução de nitrato de prata a $50 \%$, em cada extremidade da lâmina, e mistura-se as soluções com auxilio de pipeta. Cobre-se com laminnula e incuba-se o material a $50^{\circ} 60^{\circ} \mathrm{C}$, por cerca de 8 minutos, até que a solução apresente coloração castanho-dourada. Lava-se em água destilada e cora-se em solução de Giemsa tamponada a $2 \%$, por 8 minutos.

\section{Estudos Cromossômicos nas Espécies Americanas da Subordem Microchiroptera.}

Há cerca de 280 espécies das nove familias da subordem Microchiroptera que ocorrem nas Américas. Na Tabela II, que se apresenta como uma complementação da Tabela I de BAKER et al (1982), são discriminadas 195 delas, em relação às quais foram localizadas informações citogenéticas, seguindo-se basicamente a nomenclatura adotada por HONACKI et al. (1982). Para cada espécie foi referida a primeira descrição com as informações de melhor resolução, isto é, nos casos em que se conhecem os padrões de bandas $G$, só a publicação mais antiga com tais dados foi citada, sendo excluidas as demais referências que utilizaram técnicas clássicas de coloração. No entanto, procurou-se relacionar todos os estudos desenvolvidos com morcegos coletados no Brasil.

Verifica-se que cerca de 70\% das espécies representadas nas Américas foram analisadas citogenéticamente. No entanto, em relação a 10\% dessas ( 29 espécies) só há dados cariotípicos gerais, como número diplóide, número fundamental ou morfologia de autossomos e de cromossomos sexuais, e em 38\% (74 espécies) as informações derivam de preparações coradas de forma clássica, havendo, portanto, uma subestimativa da variabilidade geral. Tem-se conhecimento do padrão de bandas $\mathrm{G}$ de 90 das espécies já estudadas (46\%), do padrão de bandas C de 69 delas (35\%) e de outros padrões de bandas (Q ou R) de 9 espécies (4\%), mas em vários casos só em relação aos cromossomos sexuais. As regiões organizadoras do nucléolo foram identificadas em 20 espécies (10\%) e estudos meióticos foram realizados em 28 espécies (14\%).

Constata-se, também, a escassez de estudos por pesquisadores brasileiros, apesar da diversidade das espécies e dos tamanhos populacionais elevados com que os morcegos aparecem em praticamente todo o país.

As familias Emballonuridae, Noctilionidae, Mormoopidae e Phyllostomidae são as mais investigadas sob o enfoque citogenético, sendo que das três primeiras são conhecidos os cariótipos de todas as espécies americanas e da última há informações sobre o cariótipo de 108 das 139 espécies relacionadas. Já em relação às familias Vespertilionidae e Molossidae são conhecidos, respectivamente, os cariótipos de apenas $63 \%$ e $52 \%$ das espécies representadas nas Américas e, no caso dessa última, só duas espécies foram analisadas com técnicas de bandamento.

A familia Phyllostomidae tem o maior número de espécies representadas no Brasil. O cariótipo de Macrotus waterhousii, com $2 \mathrm{n}=46$ e FN $=60$, é considerado o mais primitivo dessa familia (PATTON \& BAKER, 1978) e a homologia de muitos segmentos cromossômicos tem sido constatada não só em espécies de várias das suas subfamilias mas também em representantes de outras familias. 
As variações cromossômicas detectadas entre a maior parte dos Phyllostomidae não são extensas, mas Uroderma bilobatum e Vampyressa pusilla (Stenodermatinae) apresentam ampla variabilidade interespecifica. Foram encontradas raças cromossômicas de $U$. bilobatum com 2 n variável de 38 a 44 e de $V$. pusilla com 2 n variável de 18 a 24 (BAKER et al., 1982, para referências), devido a ocorrência de vários tipos de rearranjos.

A seguir apresentam-se os cariótipos de algumas espécies de Phyllostomidae, com base em exemplos coletados na região noroeste do Estado de São Paulo. $\mathrm{Na}$ Figura 1 podem ser vistos os padrões de bandas $\mathrm{G}$ de Artibeus lituratus, Sturnira lilium, Vampyrops lineatus e Chiroderma doriae, da subfamilia Stenodermatinae, e de Desmodus rotundus e Diaemus youngi, da subfamilia Desmondontinae. Nos três primeiros evidencia-se extensa homologia nos padrões de bandas: não há diferenças detectáveis entre $S$. lilium (Fig. 1.B) e V. lineatus (Fig. 1.C) e estes diferem de $A$. lituratus (Fig. 1.A) em relação ao par autossômico 7 , que parece ter sofrido inversão, e aos cromossomos sexuais. Em $A$. lituratus encontra-se o sistema sexual XY $Y_{2}$, derivado de translocação en tre um autossomo $\left(\mathrm{Y}_{2}\right)$ e o cromossomo X (KASAHARA \& DUTRILLAUX, 1983) e em $S$. lilium e $V$. lineatus parece ter ocorrido também uma translocação entre tal autossomo e o cromossomo Y, configurando-se um sistema neo-XY (TUCKER, 1986). A similaridade cariotípica também ocorre entre essas espécies e Chiroderma doriae (Fig. 1.D) havendo muitos cromossomos que se afiguram iguais, como os pares $1,2,3,4$ e 6 e outros em que é possível detectar a ocorrência de inversa pericêntrica, como o par 5. Da mesma forma, os padrões de bandas G de Desmodus (Figura 1.E) e Diaemus (Fig, 1.F) evidenciam a homologia entre muitos cromossomos, como os pares 1, 2, 3, 4 e 5, e sugerem a ocorrência de inversões (par 6, por exemplo) e de outros rearranjos na diferenciação dessas espécies.

Na Figura 2 apresentam-se os padrões de bandas C de Chiroderma doriae, Artibeus planirostris e Vampyrops lineatus, da subfamilia Stenodermatinae, e de Carollia perspicillata, da subfamilia Carolliinae. A heterocromatina centromérica pode restringir-se às regiões centroméricas (Fig. 2.A), ou manifestar-se também em regiões teloméricas e intersticiais (Figura 2.B-D), apresentando variações em relação ao tamanho do bloco heterocromático.

A marcação das regiões organizadoras do nucléolo (RONs) é exemplificada na Figura 3, em relação às espécies Phyllostomus discolor, da subfamilia Phyllostominae, Artibeus planirostris e Chiroderma villosum, da subfamilia Stenodermatinae, e de Desmodus rotundus e Diaemus youngi, da subfamilia Desmodontinae. As RONs podem dispor-se em um único par de cromossomos, localizando-se em regiões teloméricas (Fig. 3.A,B) ou intersticiais (Fig. 3.C,D), ou em vários pares (Fig. 3.E). Nos casos em que há RONs em somente um par de cromossomos, elas geralmente são marcadas pela técnica de bandamento Ag.-NOR, evidenciando sua atividade constante, mas nas espécies em que há três pares de RONs encontra-se ampla variabilidade intra-especiffica no número de RONs ativas.

\section{Aplicações dos Estudos Citogenéticos.}

Há numerosas evidências de que a similaridade nos padrões de bandas é 
Revta bras. Zool.

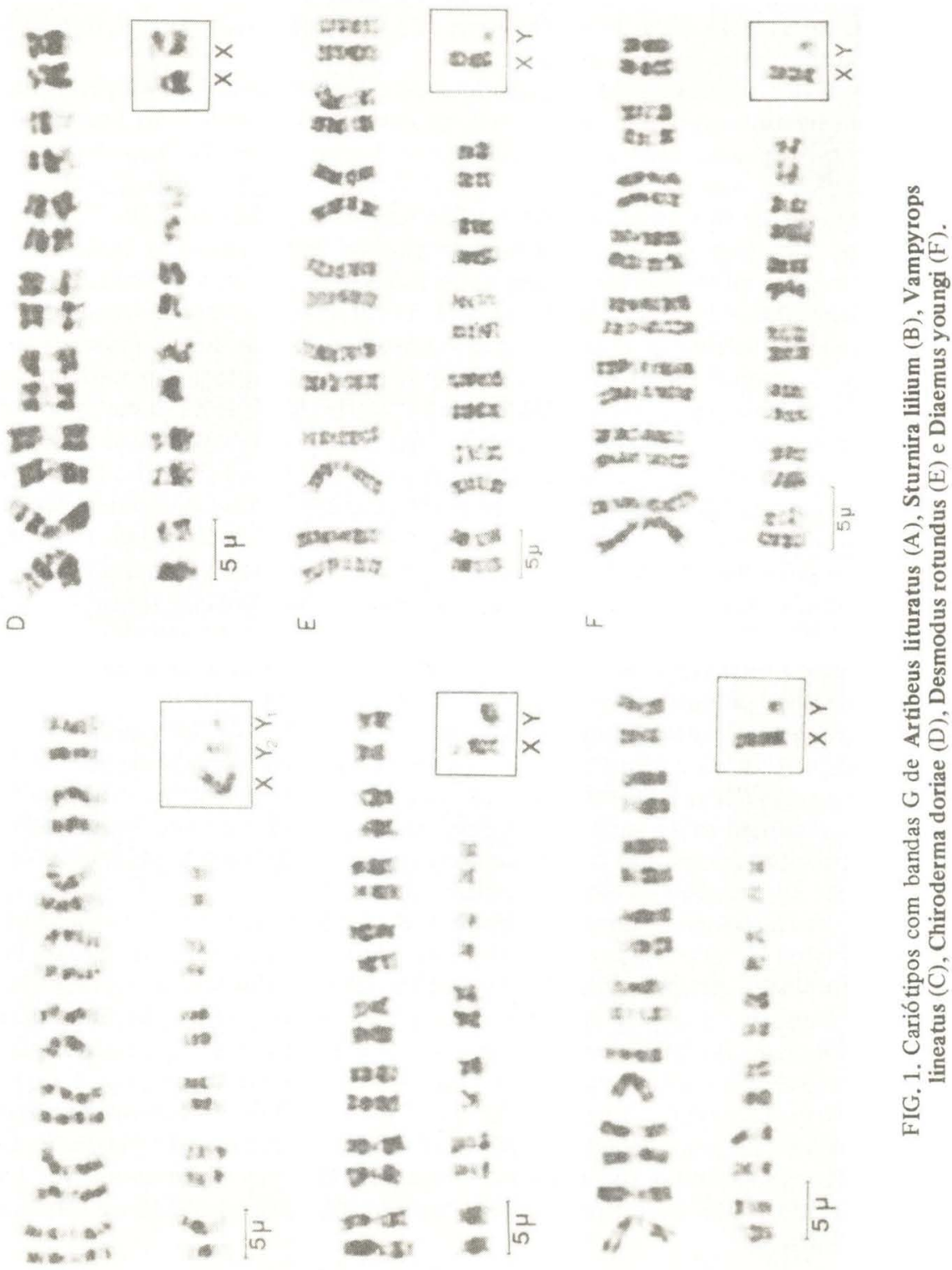


Vol. 6(2), 1989

A

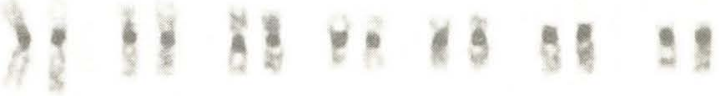

6 * 6 *

8.

5 (1)

$X Y$

B

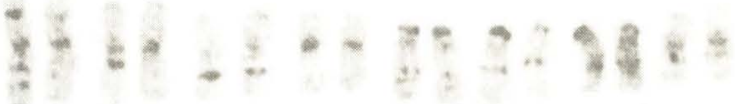

$$
\begin{aligned}
& \frac{4}{5 \mu} \\
& 25+x+4 \\
& \frac{9}{X Y}
\end{aligned}
$$

C

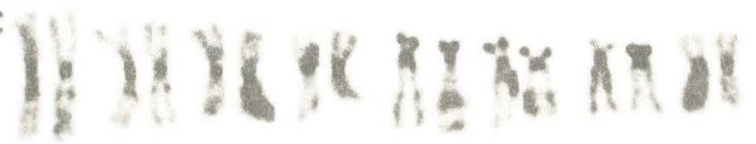

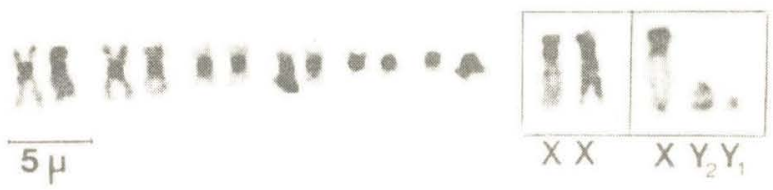

D

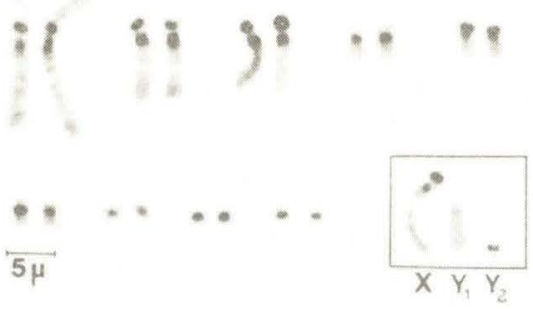

FIG. 2. Cariótipos com bandas C de Chiroderma villosum (A), Artibeus planirostris (B), Vampyrops lineatus (C) e Carollia perspicillata (D). 
Revta bras. Zool.

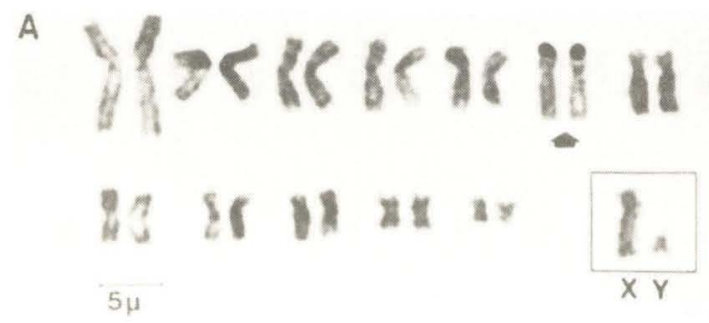

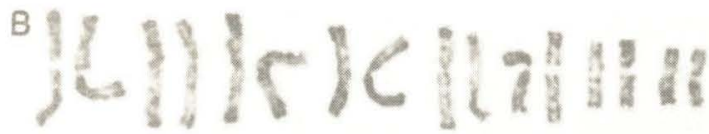

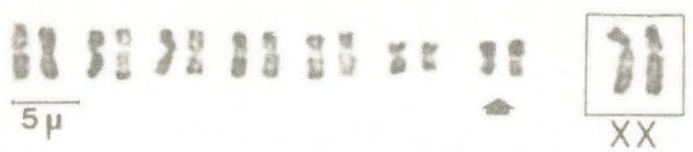

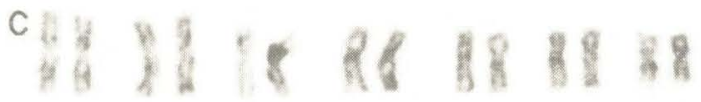

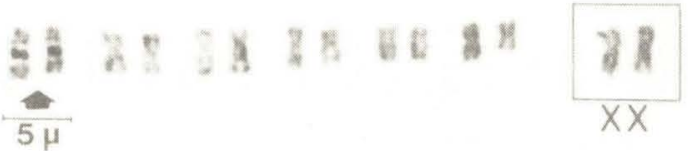

Defhy

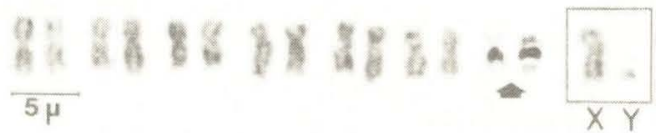

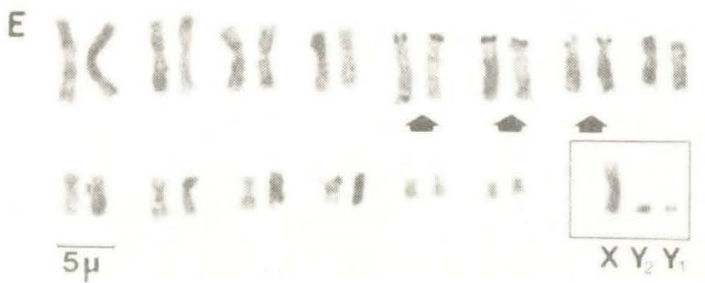

FIG. 3. Cariótipos com bandas Ag-NOR de Chiroderma villosum (A), Phyllostomus discolor (B), Desmodus rotundus (C), Diaemus youngi (D) e Artibeus planirostris (E). 
útil para a identificação de homologia genética, isto é, de uma origem evolutiva comum, até mesmo em grupos distantes, como humanos e camundongos (SAWYER \& HOZIER, 1986). Em quirópteros, com a utilização dessas técnicas pôde-se verificar que cariótipos morfologicamente muito semelhantes, como os dos gêneros Carollia (Carolliinae) e Choeroniscus (Glossophaginae), apresentarem padrões de bandas facilmente diferenciados (STOCK, 1975). O mesmo concluiu-se em relação às espécies Rhinopoma hardwickei (Rhinopomatidae) e Rousettus aegyptiacus (Pteropodidae), e esses dados permitiram que QUMSIYEH \& BAKER (1985) rejeitassem a hipótese de que a familia Rhinopomatidae se relacionasse estreitamente com os Megachiroptera, como havia sido proposto por RAY-CHAUDHURI et al. (1968), com base na similaridade das características morfológicas e nas informações cariótipicas disponiveis. Por outro lado, cariótipos aparentemente muito diferentes, como os dos sete citótipos de Rhogeessa tumida, que têm $2 \mathrm{n}=30,32,34,42,44$ ou 52 , puderam ter sua homologia rapidamente reconhecida (BICKHAM \&BAKER, 1977; BAKER et al. 1985).

Aliás, em relação ao gênero Rhogeessa há uma situação bastante interessante, pois a análise cromossômica permitiu a descrição de uma nova espécie crïptica do complexo tumida/parvula (BAKER, 1984). Essa nova espécie, designada $R$. genowaysi, tem $2 n=42$ e não se diferencia morfologicamente de $R$. tumida, mas é simpátrica no México com um citótipo dessa que tem $2 \mathrm{n}=34$ e não foram encontrados hibridos, o que indicou a ocorrência de isolamento reprodutivo.

As técnicas de bandamento têm contribuído de forma significativa para o esclarecimento dos mecanismos de evolução cromossômica entre os gêneros e as familias. Na subfamilia Stenodermatinae, por exemplo, tanto são encontrados diferentes gêneros com cariótipos altamente conservados, como é o caso de Artibeus, Sturnira e Vampyrops (BAKER, et al.,1979; MORIELLE et al.,1987a), como um gênero que engloba espécies portadoras de inúmeros e bem variados arranjos cromossômicos, como é o caso de Vampyressa (BAKER, 1979; BAKER \& BICKHAM, 1980). Também na subfamilia Glossophaginae são reconhecidos dois grupos de gêneros, um com cariótipo altamente conservado (entre os quais situa-se Glossophaga) e outro que manifesta extensa evolução cromossômica (entre os quais situa-se Anoura), o que foi bem discutido por HAIDUK \& BAKER (1982).

Outra importante conclusão, derivada dos estudos dos cromossomos tratados com as técnicas especiais para sua identificação, é relativa aos tipos de rearranjos ocorridos ao longo do processo evolutivo. A contribuição quase exclusiva das translocações robertsonianas, que era admitida pelas publicações mais antigas, foi confirmada em certos casos, como nos Rhinolophidae (ANDO et al., 1980a) e em alguns Vespertilionidae (BICKHAM, 1979a), mas ficou bem documentado que rearranjos como inversões, inserções e translocações recíprocas tiveram papel significativo em vários outros Vespertilionidae e nos Phyllostomidae (BICKHAM \& HAFNER, 1978; ANDO et al., 1980a; HAIDUK \& BAKER, 1982; STOCK, 1983; TUCKER, 1986).

Discussões sobre a filogenia das espécies, com base na homologia dos padrões de bandamento cromossômico, podem ser encontradas em relação às fa- 
milias Phyllostomidae (PATTON \& BAKER, 1978; KABER et al., 1979; BICKHAM \& BAKER, 1979; BAKER \& BICKHAM, 1980; HAIDUK \& BAKER, 1982), Vespertilionidae (BICKHAM, 1979a, b; BICKHAM \& BAKER, 1979; BAKER \& BICKHAM, 1980; STOCK, 1983, BAKER et al., 1985), Mormoopidae e Noctilionidae (PATTON \& BAKER, 1978; BAKER \& BICKHAM, 1980; SITES JR. et al., 1981).

No entanto, um caminho melhor para o entendimento do processo de especiação parece ser a análise conjunta de informações de diferentes naturezas, isto é, as interrelações das observações morfológicas, bioquímicas, ecológicas, citogenéticas e outras. Isso já vem sendo feito em relação a alguns gêneros, como Rhogeessa (BAKER et al., 1985) e Myotis (REDUKER et al., 1983) e a subfamilias, como Glossophaginae (BAKER \& BASS, 1979; BAKER et al., 1981a; HAIDUK \& BAKER, 1982; HOOD \& SMITH, 1982; GRIFFITHS, 1985), mas ainda há muito a pesquisar. Além disso, os diversos enfoques de abordagem por vezes levam a modelos de especiação diferentes e até divergentes, sendo necessário o desenvolvimento e a comprovação de hipótese que os compatibilizem.

Por outro lado, a contribuição da citogenética à sistemática de quirópteros e à formulação de hipóteses filogenéticas mais seguras poderá ser de maior valia quando informações sobre maior número de espécies estiverem disponiveis e o baixo. nǐvel de resolução atingido pelas técnicas comumente utilizadas for ultrapassado, permitindo que sejam identificados os rearranjos ocorridos entre cariótipos muito diferentes. Há perspectivas de que isso possa ocorrer brevemente, com a análise de bandas de alta resolução encontradas em cromossomos profásicos ou prometafásicos, ou induzidas durante o desenvolvimento das culturas celulares por agentes que atuam sobre o DNA, à semelhança do que vem sendo feito em roedores e outros mamiferos. 
Tabela I . Famílias e subfam11ias da sobordem Microchiroptera.

Rhinopomatidae

Emballonuridae (+)

Craseonycteridae

Nycteridae

Megadermatidae

Rhinolophidae

Noctilionidae $(++)$

Mormoopidae $(++)$

Phyllostomidae $(++)$

\section{Familias}

\section{Subfamilias}

Emballonurinae $(+)$

Diclidurinae $(++)$

Rhinolophinae

Hipposiderinae

Phyllostominae $(++)$
Glossophaginae $(++)$
Brachyphyllinae $(++)$
Carolliinae $(++)$
Stenodermatinae $(++)$
Desmodontinae $(++)$

Natalidae $(++)$

Furipteridae $(++)$

Thyropteridae $(++)$

Myzopodidae

Vespertilionidae $(+)$

Mystacinidae

Kerivoulinae

Vespertilioninae ( +)

Murininae

Miniopterinae

Tomopeatinae $(++)$

Molossidae ( + )

$(+)=$ Familias e subfamílias representadas nas Américas.

$(++)=$ Familias e subfamılias exclusivas das Américas. 
Tabela II. Estudos cromossômicos em espécies da subordem Microchiroptera que ocorrem nas Américas. 1: informações gerais; 2: foto do cariótipo usual; 3 : bandas $\mathrm{G} ; 4$ : bandas $\mathrm{C}$; 5: localização das regiões organizadoras do nucléolo; 6 : outras bandas; 7 : estudos meióti$\cos ;+$ : espécimes coletados no Brasil $;++$ : espécies que ocorrem no Brasil; $\S$ : nomenclatura conforme HONACKI et al. (1982).

Táxon

Referência

Natureza

EMBALLONURIDAE

EMBALLONURINAE

Balantiopteryx plicata

HOOD \& BAKER, 1986

3,4

++ Centronycteris maximiliani

GREENBAUM \& JONES JR., 1978

2

++ Cormura brevirostris

HOOD \& BAKER, 1986

++ Peropteryx leucoptera

BAKER et al., 1981b

BAKER et al., 1981b

2

++ Peropteryx macrotis

++ Rhynchonycteris naso

HOOD \& BAKER, 1986

++ Saccopteryx bilineata

HOOD \& BAKER, 1986

HOOD \& BAKER, 1986

3,4

++ Saccopteryx canescens

HOOD \& BAKER, 1986

3,4

++ Saccopteryx leptura

DICLIDURINAE

++ Cyttarops alecto

BAKER \& JONES JR., 1975

do estudo

++ Diclidurus albus

HOOD \& BAKER, 1986

NOCTILIONIDAE

++ Noctilio albiventris

PATTON \& BAKER, 1978

3,4

YONENAGA et al., 1969

$2+$

TOLEDO, 1973

LOPES, 1978

$2+$

BAKER et al., 1982

$2+$

3

MORMOOPIDAE

Mormoops blainvillii

Mormoops megalophylla

++ Pteronotus davyi

Pteronotus fuliginosus

++ Pteronotus gymnonotus

Pteronotus macleayii

++ Pteronotus parnellii

++ Pteronotus personatus

SITES JR. et ai., 1981

SITES JR. et al., 1981

SITES JR., et al., 1981

SITES JR. et al., 1981

SITES JR. et al., 1981

3,4

SITES JR. et al., 1981

PATTON \& BAKER, $1978 \quad 3,4$

SITES JR. et al., 1981

SITES JR. et al., 1981

PHYLLOSTOMIDAE

PHYLLOSTOMINAE

++ Chrotopterus auritus

++ Lonchorhina aurita

+ + Macrophyllum macrophyllum

Macrotus waterhousii

++ Micronycteris brachyotis

Micronycteris daviesi

++ Micronycteris hirsuta

YONENAGA et al., 1969

TOLEDO, 1973

BAKER, 1979

BAKER et al., 1982

PATTON \& BAKER, 1978

PATTON \& BAKER, 1978

TUCKER \& BICKHAM, 1986

HONEYCUTT et al., 1980

TUCKER, 1986 


$$
\begin{aligned}
& ++ \text { Micronycteris megalotis } \\
& ++ \text { Micronycteris minuta } \\
& ++ \text { Micronycteris nicefori } \\
& \quad \text { Micronycteris schmidtorum } \\
& ++ \text { Micronycteris sylvestris } \\
& ++ \text { Mimon bennettii } \\
& \quad \text { Mimon crenulatum } \\
& ++ \text { Phylloderma stenops } \\
& ++ \text { Phyllostomus discolor }
\end{aligned}
$$

++ Phyllostomus elongatus

++ Phyllostomus hastatus

++ Phyllostomus latifolius

++ Tonatia bidens

++ Tonatia brasiliense

++ Tonatia carrikeri

Tonatia schulzi

++ Tonatia silvicola

++ Trachops cirrhosus

++ Vampyrum spectrum

GLOSSOPHAGINAE

++ Anoura caudifer

Anoura cultrata

++ Anoura geoffroyi

Choeroniscus godmani

++ Choeroniscus intermedius

Choeronycteris mexicana

Glossophaga commissarisi

Glossophaga leachii

++ Glossophaga longirostris

++ Glossophaga soricina

Hylonycteris underwoodi Leptonycteris nivalis Leptonycteris sanborni Lichonycteris obscura
PATTON \& BAKER, 1978

TUCKER \& BICKHAM, 1986

TOLEDO, 1973

PATTON \& BAKER, 1978

3,4

PATTON \& BAKER, 1978

BAKER, 1973

HONEYCUTT et al., 1980

BAKER et al., 1981b

PATTON \& BAKER, 1978

BAKER, 1979

YONENAGA et al., 1969

TOLEDO, 1973

LOPES, 1978

PATTON \& BAKER, 1978

MORIELLE et al., 1985b

SOUZA, 1985

LOPES, 1978

BAKER, 1979

YONENAGA et al., 1969

TOLEDO, 1973

LOPES, 1978

PATTON \& BAKER, 1978

MORIELLE et al., 1985b

SOUZA, 1985

3,4

2

2

3

3,4

2

$2+$

$2+$

$3,4+$

3,4

$5+$

$5+$

$2+$

3

$2+$

$2+$

$2+$

3

$5+$

$5+$

HONEYCUTT et al., $1980 \quad 2$

PATTON \& BAKER, $1978 \quad 3,4$

TUCKER \& BICKHAM, 19867

PATTON \& BAKER, $1978 \quad 3,4 \S$

BAKER et al., 1981b 2

BAKER et al., $1982 \quad 3,4$

HONEYCUTT., et al., $1980 \quad 2$

TUCKER \& BICKHAM, 1986

BAKER, 1967

BAKER, 1979

YONENAGA, 1968

TOLEDO, 1973

HAIDUK \& BAKER, 1982

MORIELLE et al., 1985b

BAKER, 1979

HAIDUK \& BAKER, 1982

BAKER, 1967

STOCK, 1975

HAIDUK \& BAKER, 1982

BAKER, 1967

BAKER, 1967

BAKER, 1979

TOLEDO, 1973

BAKER \&BASS, 1979

MORIELLE et al., $1985 \mathrm{~b}$

SOUZA, 1985

HAIDUK \& BAKER, 1982

BAKER, 1973

HAIDUK \& BAKER, 1982

BAKER, 1979
$1+$

$2,7+$

3

$5+$

2

3

2

3,4

3

1

$1 \S$

1

$2+$

3,4

$5+$

$5+$

3

1

3

2 
++ Lionycteris spurrelli Lonchophylla robusta

++ Lonchophylla thomasi Monophyllus plethodon Monophyllus redmani Musonycteris harrisoni

\section{BRACHYPHYLLINAE}

Brachyphylla cavernarum Brachyphylla nana Erophylla sezekorni Phyllonycteris aphylla Phyllonycteris poeyi

\section{CAROLLIINAE}

++ Carollia brevicauda

++ Carollia castanea

+ + Carollia perspiciilata

Carollia subrufa

++ Rhinophylla fischerae

++ Rhinophylla pumilio

\section{STENODERMATINAE}

++ Ametrida centurio

Artibeus aztecus

++ Artibeus cinereus

++ Artibeus concolor

++ Artibeus fuliginosus Artibeus hartii

Artibeus hirsutus

Artibeus inopinatus

++ Artibeus jamaicensis

++ Artibeus lituratus
HAIDUK \& BAKER, 1982

BAKER, 1979

HAIDUK \& BAKER, 1982

BAKER, 1979

BAKER \& BASS, $1979 \quad 3,4$

HAIDUK \& BAKER, 1982

BAKER \& LOPES, $1970 \mathrm{~b} \quad 2$

BAKER \& BASS, $1979 \quad 3,4$

BAKER \& BASS, $1979 \quad 3,4$

BAKER \& BASS, 1979

NAGORSEN \& PETERSON, 1975

STOCK, $1975 \quad 3,4$

STOCK, $1975 \quad 3,4$

GOODPASTURE \& BLOOM, 1975

YONENAGA et al., $1969 \quad 2+$

PATHAK et al., $1973 \quad 3,4$

TOLEDO, $1973 \quad 2,7+$

HSU et al., 1975

LOPES, 1978 3,4+

BAKER, 1967

BAKER \& BLEIER, 1971

BAKER \& BLEIER, 1971

TOLEDO, $1973 \quad 2,7+$

BAKER, 1979

BAKER, 1973

BAKER \& HSU, 1970

LOPES, $1978 \quad 2+$

SOUZA \& CORREIA, $1984 \quad 5+$

TUCKER, 1986

TUCKER \& BICKHAM, $1986 \quad 7$

ARAUJO \& SOUZA, 1987a 4+

BAKER et al., 1981b 2

GARDNER et al., 1977a 1

BAKER et al., $1979 \quad 3,4 \S$

TUCKER \& BICKHAM, 1986

BAKER, 1973

BAKER, 1979

TUCKER, 1986

TUCKER \& BICKHAM, 1986

BAKER et al., $1979 \quad 3,4$

TUCKER, $1986 \quad 4,6$

TUCKER \& BICKHAM, $1986 \quad 7$

BEÇAK et al., $19692,7+$

YONENAGA et al., $1969 \quad 2+$

TOLEDO, $1973 \quad 2,7+$

LOPES, $1978 \quad 2+$

KASAHARA \& DUTRILLAUX, $1983 \quad 4,5,6+$

MORIELLE et al., 1985a 5+

TUCKER, $1986 \quad 4,6$ 


Artibeus phaeotis
++ Artibeus planirostris
Artibeus toltecus
Artibeus watsoni

Centurio senex
++ Chiroderma doriae
Chiroderma improvisum
Chiroderma salvini
++ Chiroderma trinitatum
++ Chiroderma villosum

Ectophylla alba ++ Mesophylla macconnelli

++ Pygoderma bilabiatum

++ Sphaeronycteris toxophyllum

Stenoderma rufum

Sturnira bidens

Sturnira erythromos

++ Sturnira lilium

Sturnira ludovici

Sturnira magna

Sturnira mordax

Sturnira nana

Sturnira thomasi

++ Sturnira tildae

++ Uroderma bilobatum

++ Uroderma magnirostrum

++ Vampyressa bidens

++ Vampyressa brocki

Vampyressa melissa

Vampyressa nymphaea
TUCKER \& BICKHAM, 1986

ARAUJO \& SOUZA, 1987a

BAKER, 1967

TUCKER \& BICKHAM, 1986

TOLEDO, 1973

GARDNER, 1977a

MORIELLE et al., 1985a

ARAUJO \& SOUZA, 1987a

HSU et al., 1968

TUCKER \& BICKHAM, 1986

BAKER, 1973

TUCKER, 1986

TUCKER \& BICKHAM, 1986

BAKER, 1967

VARELLA-GARCIA \&TADDEI, 1985

BAKER \& GENOWAYS, 1976

BAKER, 1979

BAKER \& GENOWAYS, 1976

TUCKER \&BICKHAM, 1986

BAKER, 1967

MORIELLE et al., 1985a

TUCKER, 1986

TUCKER \&BICKHAM, 1986

BAKER, 1979

BAKER \& HSU, 1970

MYERS, 1981

BAKER, 1979

BAKER \& LOPES, 1970a

GARDNER \& O'NEILL, 1969

BAKER, 1979

TOLEDO, 1973

LOPES, 1978

BAKER et al., 1979

SOUZA, 1985

TUCKER, 1986

TUCKER \&BICKHAM, 1986

MORIELLE et al., 1987a

BAKER, 1967

TUCKER \& BICKHAM, 1986

GARDNER, 1977a

TUCKER \&BICKHAM, 1986

BAKER, 1973

GARDNER, 1977a

BAKER, 1979

BAKER \&HSU, 1970

TUCKER \&BICKHAM, 1986

BAKER et al., 1979

TUCKER \&BICK HAM, 1986

BAKER \& LOPES, 1970a

GARDNER, 1977a

BAKER et al., 1972

GARDNER, 1977a

BAKER, 1979

TUCKER, 1986

TUCKER \& BICKHAM, 1986 
Revta bras. Zool.

++ Vampyressa pusilla

++ Vampyrodes caraccioli

++ Vampyrops brachycephalus

Vampyrops dorsalis

++ Vampyrops helleri

++ Vampyrops infuscus

++ Vampyrops lineatus

Vampyrops vittatus

DESMODONTINAE

++ Desmodus rotundus

++ Diaemus youngi

+ + Diphylla ecaudata

NATALIDAE

++ Natalus stramineus Natalus tumidorostris

FURIPTERIDAE

++ Furipterus horrens

THYROPTERIDAE

++ Thyroptera discifera

++ Thyroptera tricolor

VESPERTILIONIDAE

VESPERTILIONINAE

Antrozous pallidus

++ Eptesicus brasiliensis

++ Eptesicus diminutus

++ Eptesicus furinalis

Eptesicus fuscus

Eptesicus lynni

Euderma maculatum

++ Histiotus montanus

++ Histiotus velatus
GARDNER, 1977a

TUCKER \& BICKHAM, 1986

BAKER, 1973

TUCKER \& BICKHAM, 1986

BAKER, 1973

TUCKER \& BICKHAM, 1986

BAKER, 1973

BAKER, 1967

TUCKER \& BICKHAM, 1986

GARDNER, 1977a

TOLEDO, 1973

LOPES, 1978

SEIXAS et al., 1983

SOUZA, 1985

MORIELLE et al., 1987a

BAKER, 1979

TUCKER, 1986

FORMAN et al., 1968

YONENAGA et al., 1969

TOLEDO, 1973

LOPES, 1978

SOUZA, 1985

MORIELLE et al., 1986

ARAUJO \& SOUZA, 1987b

FORMAN et al., 1968

MORIELLE et al., 1986

CADENA \& BAKER, 1976

LOPES, 1978

ARAUJO \& SOUZA, 1987b

BAKER, 1970

BAKER \& JORDAN, 1970

BAKER et al., 1981b

BAKER et al., 1981b

BAKER et al., 1982
BICKHAM, 1979a

BAKER \& PATTON, 1967

LOPES, 1978

WILLIAMS, 1978

WILLIAMS, 1978

BICKHAM, 1979a

BICKHAM, 1979a

STOCK, 1983

WILLIAMS \& MARES, 1978

TOLEDO, 1973
2

2

2

2

3

2

7

$1 \S$

$7 \S$

1

7

1

2

7

1

$2+$

$2+$

$4+$

$5+$

$3,4,5+$

2

4,6

2

$2+$

$2+$

$3+$

$5+$

$3,4,5+$

$3,4,5+$

2

$3,4,5+$

2

$3+$

$3,4,5+$

2

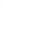


Idionycteris phyllotis

Lasionycteris noctivagans

++ Lasiurus borealis

++ Lasiurus cinereus

++ Lasiurus ega

Lasiurus intermedius

Lasiurus seminolus

++ Myotis albescens

Myotis auriculus

Myotis austroriparius

Myotis californicus

Myotis elegans

Myotis evotis

Myotis grisescens

Myotis keaysi

Myotis keenii

Myotis leibii

Myotis lucifugus

Myotis milleri

++ Myotis nigricans

++ Myotis riparius

++ Myotis simus

Myotis sodalis

Myotis thysanodes

Myotis velifer

Myotis vivesi

Myotis volans

Myotis yumanensis

Nycticeius humeralis

Pipistrellus hesperus

Pipistrellus subflavus

Plecotus rafinesquii

Plecotus townsendii

Rhogeessa genowaysi

Rhogeessa parvula

++ Rhogeessa tumida

\section{MOLOSSIDAE}

++ Eumops auripendulus

++ Eumops glaucinus

++ Eumops perotis

++ Molossops abrasus

++ Molossops greenhalli

++ Molossops temminckii

++ Molossus ater

++ Molossus molossus

Mormopterus kalinowskii
STOCK, $1983 \quad 3,4$

BICKHAM, 1979a 3,4

BICKHAM \&BAKER, 1979

BICKHAM, 1979a 3

TOLEDO, $1973 \quad 2,7+$

BICKHAM, 1979a 3

BAKER \& PATTON, $1967 \quad 2$

BICKHAM, 1979a 3

BICKHAM, 1979b 3,4

BICKHAM, 1979b 3, 4

BICKHAM, 1979b 3, 4

BAKER \& PATTON, 1967

BAKER \& PATTON, 1967

BICK HAM, 1979b 3,4

BICKHAM, 1979b 3, 3

BICKHAM, 1979b 3, 3

BICKHAM, 1979b 3, 4

BICKHAM et al., 1986

BICKHAM et al., $1986 \quad 3,4$

REDUKER et al., 1983

TOLEDO, 1973 2+

BICKHAM, 1979b 3, 4

BAKER \& JORDAN, 1970

BAKER \& JORDAN, 1970

BICKHAM, 1979b 3, 4

BICKHAM, 1979b 3,4

BICKHAM, 1979b 3,4

BAKER \& PATTON, 1967

BAKER \& PATTON, 1967

BICKHAM, 1979b 3,4

BICKHAM, 1979a 3

BAKER \& PATTON, $1967 \quad 2$

BICKHAM, 1979a 3,4

BAKER \& MASCARELLO, 1969

STOCK, $1983 \quad 3,4$

BAKER et al., 1985

BAKER et al., 1985

BICKHAM \&BAKER, $1977 \quad 3,4$

BAKER et al., 1985

TOLEDO, 1973

WARNER et al., 1974

WARNER et al., 1974

MORIELLE et al., 1987b 3, 4, 5+

BAKER, 1970

TOLEDO, 1973

WARNER et al., 1974

BAKER, 1970

GARDNER, 1977b 2

TOLEDO, 1973

WARNER et al., 1974

LOPES, 1978

2, 7+

2

$2+$

2

$2+$

$1 \S$ 
Revta bras. Zool.

++ Nyctinomops aurispinosus

Nyctinomops femorosaccus

++ Nyctinomops laticaudatus

++ Nyctinomops macrotis

Promops centralis

++ Promops nasutus

++ Tadarida brasiliensis
WARNER et al., 1974

PATTON \& BAKER, 1966

WARNER et al, 1974

WARNER et al., 1974

BAKER, 1970

WARNER et al., 1974

WAINBERG, 1966

BAKER et al., 1982

\section{AGRADECIMENTOS}

Ao $\mathrm{CNPq}$, pelo auxilio financeiro, aos biológos Eliana Morielle, Eny Maria Goloni, Rita Beatriz de Seixas e Wagner André Pedro e ao Sr. Josué Rodrigues dos Santos, pelo valioso auxilio técnico.

\section{REFEREANCIAS}

ANDO, K; T. TAGAWA, \& T. A. UCHIDA, 1977. Considerations of karyotypic evolution within Vespertilionidae. Experientia, 33: 877-879.

ANDO, K. T. TAGAWA \& T. A. UCHIDA, 1980a. The C-banding pattern of 6 Japanese species of vespertilionine bats (Mammalia: Chiroptera). Experientia, 36: 653-654.

ANDO, K, T. TAGAWA \& T. A. UCHIDA., 1980b. Karyotypes of Taiwanese and Japanese bats belonging to the families Rhinolophidae and Hipposideridae. Cytologia, 45:423-432. 
ARAÚJO, M. C. P. \& M.J.SOUZA, 1987a. Análise comparativa da distribuição de heterocromativa constitutiva no gênero Artibeus (Chiroptera). Anais do IV Encontro de Genética do Nordeste, Olinda, PE.

ARAÜJO, M. C. P. \& M. J. SOUZA, 1987b. Análise comparativa dos padrões de bandamento cromossômico em Desmodus rotundus e Dyphilla ecaudata. Ci. e Cult., 39(7):755 (Suplemento).

BAKER, R. J., 1967. Karyotypes of bats of the family Phyllostomidae and their tax onomic implications. Southwest. Natur., 12:407-428.

BAKER, R. J., 1970. Karyotypic trends in bats. In: Wimsatt, W. A. (Ed.). Biology of Bats. Academic Press, New York.

BAKER, R. J., 1973. Comparative cytogenetics of the New World leaf-nosed bats (Phyllostomatidae). Period. biol., 75:37-45.

BAKER, R. J., 1979. Karyology. In: Baker, R. J., Jones Jr., J. K. e Cartes, D. C. (Eds). Biology of Bats of the New World Family Phyllostomatidae. Vol. 16. Special Publication, The Museum, Texas Tech University, Lubbock, TX, pp. 107-155.

BAKER, R. J., 1984. A sympatric cryptic species of mammal: a new species of Rhogeessa (Chiroptera: Vespertilionidae). Syst. Zool., 33:178-183.

BAKER, R. J. \& R. A. BASS, 1979. Evolutionary relationship of the Brachyphyllinae to the glossophagine genera Glossophaga and Monophyllus. J. Mamm. 60:364-372.

BAKER, R. J. \& W.J.BLEIER, 1971. Kayotypes of bats of the subfamily Carollinae (Mammalia: Phyllostomatidae) and their evolutionary implications. Experientia, 27:220222.

BAKER, R. J.\& J.W.BICKHAM, 1980. Karyotypic evolution in bats: evidence of ex tensive and conservative chromosomal evolution in closely related taxa. Syst. Zool., 29:239-253.

BAKER, R. J. \& H. H. GENOWAYS, 1976. A new species of Chiroderma from Guadeloupe, West Indies (Chiroptera: Phyllostomatide). Occas. Papers Mus. Texas Tech Univ., 39: $1-9$.

BAKER, R. J. \& T.C.HSU, 1970. Further studies in the sex chromosome systems of American leaf-nosed bats (Chiroptera: Phyllostomatidae). Cytogenetics, 9:131-138.

BAKER, R. J. \& J. K. JONES JR, 1975. Additional records of bats from Nicaragua, with a revised cheklist of Chiroptera. Occas. Papers Mus. Texas Tech Univ. 34:1-7.

BAKER, R. J. \& R. G. JORDAN, 1970. Chromosomal studies of some neotropical bats of the families Emballonuridae, Noctilionidae, Natalidae and Vespertilionidae. Caryologia, 23:595-604.

BAKER, R. J. \& G. LOPES, 1970a. Chromosomal variation in bats of the genus Uroderma (Phyllostomatidae). J. Mamm., 51:786-789.

BAKER, R. J. \& G. LOPEZ, 1970b. Karyotypic studies of the insular population of bats on Puerto Rico. Caryologia, 23:465-472.

BAKER, R. J. \& J. J. MASCARELLO, 1969. Chromosomes of some vespertilionid bats of the genera Lasiurus and Plecotus. Sow thwest. Natur. 14:249-251. 
BAKER, R. J. \& J. L. PATTON, 1967. Karyotypes and Karyotypic variation of North American vespertilionid bats. J. Mamm., 48:270-286.

BAKER, R. J.;A. L. GARDNER \& J. L. PATTON, 1972. Chromosomal polymorfism in the Phyllostomatid bat, Mimon crenulatum Geoffroy . Experientia, 28:969-970.

BAKER, R. J.; R. A. BASS \& M. A. JOHNSON, 1979. Evolutionary implications of chromosomal homology in four genera of stenodermine bats (Phyllostomatidae: Chiroptera). Evolution, $33: 220-226$.

BAKER, R. R. J.; R. L. HONEYCUTT, M. L. ARNOLD, A. V. SARICH \& J. K. JONES JR., 1981a. Eletrophoretic and immunological studies on the relationship of the Brachyphyllinae and the Glossophaginae. J. Mamm., 62:665-672.

BAKER, R. J.; H. H. GENOWAYS \& P. A. SEYFARTH, 1981b. Results of the Alcoa Foundation Suriname Expeditions. VI. Additional chromosomal data for bats (Mammalia: Chiroptera). from Suriname. Ann. Carnegie Mus., 50:333-344.

BAKER, R. J.; M. W. HAIDUK; L. W. ROBBINS; A. CADENA \& B. F. KOOP, 1982. Chromosomal studies of South American bats and their systematic implications. In: Mares. M. A. e Genoways, H. H. (Eds.). Mammalian Biology in South America, Vol. 4. Special Publication Series, Pymatuning Laboratory of Ecology, University of Pittsburgh, Penn., pp. 303-327.

BAKER, R. J.; J. W. BICKHAM \& M. L. ARNOLD, 1985. Chromosomal evolution in Rhogeessa (Chiroptera: Vespertilionidae): possible speciation by centric fusions. Evolution, 39:233-243.

BEÇAK, M. L.; R. BATISTIC, L. D. VIZOTTO \& W. BEÇAK, 1968. Mecanismo de determinação do sexo $\mathrm{XY}_{1} \mathrm{Y}_{2}$ em Artibeus litturatus litturatus (Chiroptera - Phyllostomatidae). Ci. e Cult., 20:173.

BEÇAK, M. L.; R. F. BATISTIC; L. D. VIZOTTO \& W. BEÇAK, 1969. Sex determining mechanism $X_{1} Y_{2}$ in Artibeus lituratus (Chiroptera, Phyllostomidae), Experientia, 25: 81-83.

BICKHAM, J. W., 1979a. Chromosomal variation and evolutionary relationships of vespertilionid bats. J. Mamm., 60:350-363.

BICKHAM, J.W., 1979b. Banded Karyotypes of 11 species of American bats (genus Myotis). Cy tologia, 44:789-797.

BICKHAM, J. W. \& R. J. BAKER, 1977. Implications of chromosomal variation in Rhogheessa (Chiroptera: Vespertilionidae). J. Mamm., 58:448-453.

BICKHAM, J. W. \& R. J. BAKER, 1979. Canalization model of chromosomal evolution. Bull. Carnegie Mus. Nat. Hist., 13:70-84.

BICKHAM, J. W. \& J. C. HAFNER, 1978. A chromosomal banding study of three species of vespertilionid bats from Yuguslavia. Genetica, 48:1-3.

BICKHAM, J. W.; K. McKEE \& D. A. SCHLITTER, 1986. Chromosomal variation among seven species of Myotis (Chiroptera: Vespertilionidae). J. Mamm., 67: 746-750.

CADENA, A. \& R. J. BAKER, 1976. Cariotipos de los murcielagos vampiros (Chiroptera: Desmodinae). Caldasia, 11:159-163. 
CAPANNA, E. \& M. V. CIVITELLI, 1970. Chromosomal mechanisms in the evolution of chiropteran karyotype; chromosomal tables of Chiroptera. Caryologia, 23:79-111.

CONSTANTINE, D. G., 1970. Bats. in relation to the health, welfare and economy of man. Pp. 319-449. In: Wimsatt, W. A. (Ed.), Biology of Bats, New York, Academic Press, Pp. 1-477.

De GrOUCHY, J. \& C. TURLEAU, 1977. Atlas des maladies Cromossomiques. Paris, Expansion Scientifique Française.

EL-ANSARY, E. H.; D. J. GORDON; R. D. TEE \& A. J. N. TAYLOR, 1987. Respiratory allergy to inhaled bat guano. Lancet (1),8527:316-318.

FREEMAN, D. W., 1981. A multivariate study of the family Molossidae (Mammalia, Chiroptera): morphology, ecology, evolution. Fieldiana Zoology New Series, 7:1-173.

FORMAN, G. L.; R. J. BAKER \& J. GERBER, 1968. Commments on the systematic status of vampire bats (Family Desmodontidae). Syst. Zool., 17:417-425.

GARDNER, A. L., 1977a. Chromosomal variation in Vampyressa and a review of chromosomal evolution in the Phyllostomidae) (Chiroptera). Syst. Zool., 26:300-318.

GARDNER, A. L. 1977b. Taxonomic implications of karyotypes of Molossops and Cynomops (Mammalia: Chiroptera). Proc. Biol. Soc. Wa shington, 89:545-550.

GARDNER, A. L. \& J. P. O NEILL, 1969. The taxonomic status of Sturnira bidens (Chiroptera: Phyllostomidae) with notes on its karyotype and life history. Occas. Papers. Mus. Zool., Louisiana State University, 38:1-8.

GOODPASTURE, C. \& S. E. BLOOM, 1975. Visualization of nucleolar organizer regions in mammalian chromosomes using silver staining. Chromosoma, 53:37-50.

GRENBAUM, I. F. \& J. K. JONES JR,, 1978. Noteworthy records of bats from E1 Salvador, Honduras and Nicaragua, Occas. Papers Mus. Texas Tech. Univ., 55: 1-7.

GRIFFISTHS, T, A., 1985. Molar cusp patterns in the bat genus Brachyphylla: some funcional and systematic observations. J. Mamm. 66: 544-549.

HAIDUK, M. W. \& R. J. BAKER, 1982. Cladistical analysis of G-banded chromosomes of nectar feeding bats (Glossophaginae; Phyllostomidae). Syst. Zool., 31:252-265.

HANDLEY JR., C. O., 1976. Mammals of the Smithsonian Venezuelan Project. Brigham Young Univ. Sci. Brell., 20:1-89.

HARADA, M; S. YENBUTRA, T. H. YOSIDA \& S. TAKADA, 1985. Cytogenetical study of Rhinolophus bats (Chiroptera, Mammalia) from Thailand. Proc. Japan Acad., $61: 455$ 458 .

HONACKI, J. H:; K. KINMAN, \& J. W. KOEPPL, (eds.), 1982. Mammal Species of the World: a Taxonomic and Geographic Reference. Association Systematics Collections, Kansas.

HOWELL, W. M. \& A. D. BLACK, 1980. Controlled silver staining of nucleolus organizer regions with a protective colloidal developer: a 1-step method. Experientia, 36:10141015 .

HONEYCUTT, R. L.; R. J. BAKER \& H. H. GENOWAYS, 1980. Results of the Alcoa 
Foundation - Suriname expeditions. III. Chromosomal data for bats (Mammalia: Chiroptera) from Suriname. Ann. Carnegie Mus., 49:237-250.

HOOD, C. S. \& R. J. BAKER, 1986. G- and C- banding chromosomal studies of bats of the family Emballorunidae. J. Mamm., 67:705-711.

HOOD, C. S. \& J. D. SMITH, 1982. Cladistical analysis of female reproductive histomophology in phyllostomatoid bats. Syst. Zool. 31:241-251.

HOOD, C. S. \& J. D. SMITH, 1983. Histomorphology of the female reproductive tract in phyllostomoid bats. Occas. Papers Mus. Texas Tech Univ ., 86:1-38.

HSU, T, C.; R. J. BAKER \& T. UTAKOJI, 1968. The multiple sex chromosome system of American leaf-nosed bats (Chiroptera, Phyllostomidae). Cytogenetics, 7:27-38.

HSU, T. C.; S. E. SPIRITO \& M. L. PARDUE, 1975. Distribution of $18+28$ S ribosomal genes in mammalian genomes. Chromosoma, 53:25-36.

KASAHARA, S. \& B.DUTRILLAUX, 1983. Chromosome banding patterns of four species of bats, with special reference to a case of X-autosome translocation. Ann. Genet., 26: 197-201.

KOOPMAN, K. F., 1970. Zoogeography of bats. In: Slaughter, B. H. e Walton, D. W. (Eds.). About Bats: a Chiropteran Biology Symposium. Southern Methodist University Press, Dallas.

KOOPMAN, K. F., 1984. A Synopsis of the families of bats. Bat Research News, 25 :25-29.

KOOPMAN, K. F. \& J. K. JONES JR, 1970. Classification of bats. In: Slaughter, B. H. e Walton, D. W. (Eds). About Bats: a Chiropteran Biology Symposium.Southern Methodist University Press, Dallas.

LEE, M. R. \& F. F.B. ELDER, 1980. Yeast stimulation of bone marrow mitosis for cy togenetic investigations. Cy togenet. Cell Genet., 26:36-40.

LOPES, M. J. S., 1978. Contribuição para o estudo citogenético de morcegos: Análise de 15 espécies. Dissertação de Mestrado, Institu to de Biociências, USP, São Paulo.

MORIELLE, E.; M. VARELLA-GARCIA \& V. A. TADDEI, 1985a. Regiões organizadoras do nucléolo em morcegos dos gêneros Artibeus e Chiroderma (Chiroptera, Phyllostomidae). Resumos do $4^{\circ}$. Encontro de Geneticistas Paulistas, São José do Rio Preto: 36.

MORIELLE, E.; M. VARELLA-GARCIA \& V.A.TADDEI, 1985b. Regiões organizadoras do nucléolo em morcegos das subfamilias Phyllostomidae e Glossophaginae (Chiroptera, Phyllostomidae). Resumos do $12^{\circ}$. Colóquio de Incentivo à Pesquisa; São José do Rio Preto: 14.

MORIELLE, E.; E. M. GOLONI, M. VARELLA-GARCIA \& V. A. TADDEI, 1986. Análise cariotípica em morcegos hematófagos (Chiroptera, Desmodontinae). Ci.e Cult., 38 (7): 938 (Suplemento).

MORIELLE, E.;M. E. GOLONI; M. VARELLA-GARCIA \& V. A. TADDEI, 1987a. Evolução cariotípica na subfamília Stenodermatinae (Chiroptera; Phyllostomidae), com base nos padrões de bandas G, C e NOR. Ci.e Cult., 39(7): 778 (Suplemento),

MORIELLE, E; E. M. GOLONI; M. VARELLA-GARCIA \& V. A. TADDEI, 1987b. Análise cariotípica de Eumops glaucinus (Chiroptera, Molossidae). Resumos do $14^{\circ}$. Colóquio 
Vol. 6(2), 1989

de Incentivo à Pesquisa, São José do Rio Preto: 44.

MYERS , P. 1981. Observation on Pygoderma bilabiatum (Wagner). Zeitschrift fur Saugetierkunde, 46:146-151.

NAGORSEN, D. W. \& R. L.PETERSON, 1975. Karyotypes of six species of bats (Chiroptera) from the Dominican Republic. Life Sci. Contrib., Royal Ontario Mus. 28:1-8.

OBARA, Y.; T. TOMIYASU, \& K. SAITOH, 1976. Chromosome studies in the Japanese vespertilionid bats. II. G-banding pattern of Pipistrellus abramus TEMMINCK. Proc. Japan Acad. 52:383-386.

PATHAK, S.; T. C.HSU \& T. UTAKOJI, 1973. Relationships between patterns of chromosome banding and DNA synthetic sequences: a study on the chromosomes of the Seba's fruit bat Carollia perspicillata. Cy togenet. Cell Genet., 12:157-164.

PATTON, J. L. \& R. J. BAKER, 1966. Somatic chromosome numbers of 31 species of North American Chiroptera. Mammalian Chromosomes Newsletter, 20 :66-67.

PATTON, J. L. \& R. J. BAKER, 1978. Chromosomal homology and evolu tion of phyllostomatoid bats. Syst. Zool. 27:449-462.

PATTON, J. L. \& A. L. GARDNER, 1971. Parallel evolution of multiple sex-chromosome systems in the Phyllostomatid bats, Carollia and Choeroniscus. Experientia, 27:105-106.

QUMSIYEH, M.Z. \& R.J.BAKER, 1985.G-and C-banded karyotypes of the Rhinopomatidae (Microchiroptera). J. Mamm., 66:541-544.

RAY-CHAUDKURI, S. P.; S. PATHAK \& T.SHARMA, 1968. Chromosomes and affinities of Pteropodidae (Megachiroptera) and Rhinopomatidae (Microchiroptera). The Nucleus, 1968: 96-101.

REDUKER, D. W.; T. L. YATES \& I. F. GRENBAUM, 1983. Evolutionary affinities among Southwestern long-eared Myotis (Chiroptera: Vespertilionidae). J. Mamm., 64:666-677.

SAZIMA, I., 1978. Aspectos do comportamento alimentar do morcego hematófago, Desmodus rotundus. Biol. Zool. USP, 3:97-120.

SAWYER, J. R. \& J. C. HOZIER, 1986. High resolution of mouse chromosomes: banding conservation between man and mouse. Science, 232: 1632-1635.

SEIXAS, R. B.; M. VARELLA-GARCIA \& V. A. TADDEI, 1983. Polimorfismo de heterocromatina constitutiva em Vampyrops lineatus (Chiroptera, Phyllostomidae, Stenodermatinae). Resumos do $10^{\circ}$. Colóquio de Incentivo à Pesquisa, São José do Rio Preto.

SITES JR., J. W.; J. W. BICKHAM \& M. W. HAIDUK, 1981. Conservative chromosomal change in the bat family Mormoopidae. Can. J. Genet. Cytol., 23:459-467.

SMITH, J. D., 1972. Systematics of the chiropteran family Mormoopidae. Mix. Publ. Mus. Nat. Hist., Univ. Kansas, 56:1-132.

SOUZA, M. J \& S. I. C. CORREIA, 1984. Estudo das regiões organizadoras do nucléolo (RONs) em exemplares de Artibeus coletados em Pernambuco (Chiroptera, Phyllostomatidae). Ci. e Cult., 36(7):850 (Suplemento). 
SOUZA, M. J., 1985. Regiões organizadoras do nucléolo em seis espécies de morcegos da famúlia Phyllostomidae. Ci. e Cult., 37(7):739-740 (Suplemento).

STOCK, A. D., 1975. Chromosome banding pattern homology and its phylogenetic implications in the bat genera Carollia and Choeroniscus. Cytogenet. Cell Genet., 14:34-41.

STOCK, A. D., 1983. Chromosomal homologies and phylogenetic relationships of the vespertilionid bat genera Euderma, Idionycteris and Plecotus. Cytogenet Cell Genet., $35: 136-140$.

SUMMER, A. T., 1972. A simple technique for demonstrating centromeric heterochromatin. Exp. Cell Res., 75 :304-306.

TADDEI, V. A., 1973. Phyllostomidae da região norte-ocidental do Estado de São Paulo. Tese de Doutorado, Fac. Fil. Ciênc. Letr. de São José do Rio Preto, São Paulo.

TADDEI, V. A., 1976. The reproduction of some Phyllostomidae (Chiroptera) from the Northwestern region of the State of São Paulo. Bol. Zool., Univ. S. Paulo, 1:313-330.

TADDEI, V. A., 1983. Morcegos: algu mas considerações sistemáticas e biológicas. Bol. Téc. CATI, 172:1-30.

TADDEI, V. A.; R. B. SEIXAS \& A. L. DIAS, 1986. Noctilionidae (Mammalia, Chiroptera) do sudeste brasileiro. Ci. e Cult., 38:904-916.

TOLEDO, L. A., 1973. Estudos citogenéticos em morcegos brasileiros (Mammalia-Chiroptera). Tese de Doutorado. Faculdade de Ciências Médicas e Biológicas de Botucatu, SP.

TUCKER, P. K., 1986. Sex chromosome-autosome translocations in the leaf-nosed bats, family Phyllostomidae. I. Mitotic analyses of the subfamilies Stenodermatinae and Phyllostominae. Cytogenet. Cell Genet., 43:19-27.

TUCKER, P. K. \& J. W. BICKHAM, 1986. Sex chromosome-autosome translocations in the leaf-nosed bats, family Phyllostomidae. II. Meiotic analyses of the subfamilies Stenodermatinae and Phyllostominae. Cytogenet. Cell Genet. 143:28-37.

VARELLA-GARCIA, M. \& V. A. TADDEI, 1985. Análise cariotípica de Chiroderma doriae (Chiroptera, Phyllostomidae). Ci. e Cult., 37(7): 790 (Suplemento).

VOLLETH, M,, 1985. Chromosomal homologies of the genera Vespertilio, Plecotus e Barbastella (Chiroptera: Vespertilionidae. Genetica, 66:231-236.

WAINBERG, R. L. 1966. Cytotaxonomy of South American Chiroptera, Arch. Biol., 77: 111-123.

WAINBERG, R. L.; L. H. D. BIANCHINI; J. J. BIANCHINI \& G. E. P. ACTIS-DATO, 1974. Uniformidad cariotípica y radiacion adaptativa en "Eumops" $y$ Molossus (Chiroptera, Molossidae). Physis Secc C Buenos Aires, 33: 249-254.

WALKER, E. P., 1975. Mammals of the World. Johns Hopkins Univ. Press, Baltimore.

WARNER, J. W.; J. L. PATTON, A. L. GARDNER \& R. J. BAKER, 1974. Karyotypic analyses of twenty-one species of molossid bats (Molossidae: Chiroptera). Canadian J. Genet. Cytol., 16:165-176. 
Vol. 6(2), 1989

WILlIAMS, C. F., 1986. Social organization of the bat, Carollia perspicillata (Chiroptera, Phyllostomidae). Ethology, 71:265-282.

WILLIAMS, D. F., 1978. Tax onomic and karyologic comments on small brown bats, genus Eptesicus, from South America. Ann. Carnegie Mus., 47:361-383.

WILLIAMS, D. F. \& M. A. MARES, 1978. Karyologic affinities of the South American big-eared bat, Histiotus montanus (Chiroptera, Vespertilionidae). J. Mamm., 59:844846.

WILLIG, M. R., 1983. Composition, microgeographic variation and sexual dimorphism in caatingas and cerrado bat communities from Northeast Brazil. Bull. Carnegie Mus. Nat. Hist., 23:1-131.

YONENAGA, Y., 1968. Estudos cromossômicos em espécies de Chiroptera. Ci. e Cult., $20: 172$.

YONENAGA, Y.; O. FROTA-PESSOA \& K. R. LEWIS, 1969. Karyotypes of seven species of Brazilian bats. Caryologia, 22:63-78. 